\title{
Issues of Logicism and Objectivity
}

\author{
Trudy Govier
}

Department of Philosophy

University of Lethbridge

Lethbridge, Alberta

Canada

Govier@shaw.ca

\begin{abstract}
This essay treats several themes central to Harald Wohlrapp's discussion of the notion of conductive argument, as that idea has been developed by Trudy Govier and others. Central to the exploration are two issues. The first is Wohlrapp's notion of Govier's account as flawed by what he considers to be logicism. The second is his charge that key terms employed by Govier and others in efforts to provide assessment guidelines for conductive arguments are misleadingly quantitative in their implications.
\end{abstract}

Résumé: Cet essai traite plusieurs thèmes centraux de la discussion de Harald Wohlrapp sur la notion d'argument conducteur, puisque cette idée a été développée par Trudy Govier et d'autres. Il y a deux problèmes au centre de l'exploration. Le premier est la notion de Wohlrapp que le récit de Govier a des défauts qui relèvent de ce qu'il considère comme un logicisme. La seconde est sa charge que les termes clés employés par Govier et d'autres dans leurs efforts à fournir des lignes directrices d'évaluation pour les arguments conducteurs sont trompeusement quantitatifs dans leurs implications.

Keywords: conductive arguments, metaphor, objectivity, Wohlrapp, Govier, logicism, premises, conclusion, relevance, retroflexivity, frames

In his book The Concept of Argument Harald Wohlrapp offers an account of the role of argument in human life. In life, we need orientation, a sense of how to go on. Sometimes our old theories are not adequate and we need new theory. When a new theory is proposed, there is a kind of gap that we may call a gap in orientation. This is where argument enters the picture. Wohlrapp's theory is substantial and ambitious. I concentrate here only on aspects of his account that are relevant to the treatment of pro and con argumentation, a type of what has been called conductive argument.

Though initially intrigued by my efforts to describe and explore conductive argument, Harald Wohlrapp later concluded that my treatments were seriously flawed and that an alternative approach can serve to replace that problematic and much con- 
tested conception. Much of the difference between our approaches concerns what he deems to be a logicistic approach (referred to here as logicism) on my part (see pp. 255-256) ${ }^{1}$.

\section{Logicism}

By logicism, Wohlrapp does not mean formalism. Nor does he allude to the thesis of logicism in the philosophy of mathematics. The problem of logicism, on his account, is that it would have us articulate the premises and conclusion of an argument in just so many words, neglecting the fact that with conductive arguments, one finds "an extension of logical reasoning." (256) A formalist would insist that the premises and conclusion of an argument be translated into the symbols of a formal deductive system, and the argument as formally represented should be evaluated for its deductive validity according to the rules of that system. Neither in practice nor in theory have I ever endorsed such an approach; nor does Wohlrapp imply that I endorse it. What he finds to be logicistic, and as such, objectionable, is something else, something short of formalism as commonly understood. It is the representation of an argument as constituted of claims amounting to premises and conclusion-what he refers to as a PPC model of an argument. What is involved in this representation of an argument is extracting from spoken or written discourse claims (premises) cited as providing reason for a further claim (conclusion), so that one has articulated a product of explicit statements that one can scrutinize and assess. I would add that there can of course be sub-arguments, multiple conclusions, more premises, and so on. Wohlrapp would of course acknowledge that sort of point. 'PPC' is used by him as a label for the approach of articulating the premises and conclusion in order to evaluate the logical cogency of an argument. He finds this approach artificial and "as restrictive as a tight corset." (255)

Harald Wohlrapp thinks that informal logicians have been unduly influenced by traditions of formal logic when they take such an approach - as they characteristically do. For him, PPC models are a legacy of formal logic and not a positive legacy at that. I would urge that the identification of statements as premises and conclusions is a pre-formal task. Even if one insists on formalization, as a formalist would do (and as I do not and never

\footnotetext{
${ }^{1}$ All page numbers refer to Harald R. Wohlrapp, The Concept of Argument: A Philosophical Foundation, translated from the German by Tim Personn in cooperation with Michael Weh.
} 
have), one needs to know which statements would need to be formalized, which claims are being made and put forward as reasons for just which other claims. Only after having identified premises and conclusions will one undertake the task of formalizing them.

One potential problem with the PPC approach is that the natural language discourse can be misinterpreted, so that the claims explicitly stated and deemed to be premises and conclusions are not accurately drawn from spoken or written discourse. For example, a person might fail to detect irony in a discourse and erroneously deem a sarcastic side remark to be a premise. Or she might fail to understand that a rhetorical question, in the context in which it appears, is a way of asserting the conclusion of the argument. Whether a particular version of premises and conclusions amounts to a correct interpretation of some discourse can be discussed, and proposed renditions of the premises and conclusion can be corrected if they are deemed to be erroneous. If amendment is appropriate, an arguer or interpreter can go through a process with a discussant to explore that issue. That is to say, if person \#1 represents a speech as expressing some particular PPC argument and person \#2 thinks \#1 has made a mistake in so doing, \#2 can say that to \#1 and they can proceed to discuss and explore the issue, referring back to the original discourse in its context to seek a better interpretation that is acceptable to both. If more discussants arrive on the scene, they can contribute further questions and suggestions. There is nothing about representing claims as carefully articulated premises and conclusions that will forbid or cut off such a discussion. I submit accordingly that the allegedly tight corset is not as tight as Wohlrapp seems to suppose.

However, this is not the core of the problem. Wohlrapp's concern is not with the possibility of mis-identifying or misstating premises and conclusions. This is not quite what is at stake in what he terms a logicistic approach. On his view, the issue is not one of misinterpretation. Rather, it is much deeper; he has a dialogical model of argument and is concerned with process, not product. A PPC model (referred to in some texts including my own as a standardized argument) represents a product rather than a process.

The paradigmatic role of such a product representation of argument presents a problem for Wohlrapp because it is the central feature of an approach that does not suit his overall theory with regard to the suitability of a thesis to serve as new orientation. On his account, argument should be thought of not as an argument (PPC) but rather as argumentation, a process within 


\section{Trudy Govier}

which various arguments (considerations purporting to justify or object to a thesis) can arise, be developed, criticized, and if appropriate, amended. (We may note here that in explaining the matter, it seems as though smaller arguments are constituents of the larger and broader social process of argumentation. I think this impression merits careful study.) On Wohlrapp's account, after a discussion, the first thesis put forward may be changed and successor theses can be stated and discussed. Within such a process, he interestingly points out that what tradition would regard as conclusions can even affect what tradition would regard as premises, in at least this sense: if discussants adapt their sense of what claim is at issue, they may adapt also the selection of claims that could support it. (Note that to make this point, Wohlrapp uses the notions of premises and conclusions that he has rejected as being, in a sense he deems objectionable, logicist.)

But the fact that Wohlrapp's account stresses process does not suffice to establish the incorrectness of the many accounts, including my own, that focus on arguments as products, constituted of premises and conclusions. His account is not one in which the argument as product with premises and conclusions is the central focus. That focus reflects his decisions and interests. However it does not show that the different product approach he brands as 'logicistic' amounts to a deep error (253-255). In fact, as noted here, there persist some indications that PPC structures will be spotted and evaluated by Wohlrapp himself at key points, as when he refers to a state of arguments for and against the thesis, the emergence of new arguments, or the quality of arguments.

The second alleged problem with the PPC approach, for Wohlrapp, is that it leads to a kind of straitjacket or tight corset. It is too fixed; it is limited and limiting; it is not open, on his view. And yet, as we have seen, the fact that one begins a discussion by considering an explicit claim to be a premise or conclusion does not prohibit or cut off discussion about the status or accuracy of that claim. When there are discussants, they can amend, revise, or reject that claim or amend their ideas about its role in an argument. When a solo thinker is understood as evaluating claims in a kind of dialogue with him or herself (such a extension is needed, to preserve the conception of argument as dialogical), that person can assess his or her understanding of what is claimed and amend his articulation of premises and conclusions. The PPC approach is less fixed and limited than Wohlrapp maintains. 
Seeking to avoid logicism, which he regards as profoundly mistaken, Wohlrapp develops his own approach to pro and con arguments. He urges that employing a process approach such as his will mean that the somewhat mystifying conception of a conductive argument can be replaced. With regard to what, on a standard model, would be regarded as premises, he urges that discussants seek further information as to their relevance and credibility. (Persons seeking, in a PPC framework, to evaluate the reasons put forward for a claim can also, of course, also evaluate stated premises for their relevance and credibility.) Wohlrapp comes to recommend retroflexivity: premises are understood with reference to the conclusion, which in turn is understood with reference to them. Relevance may be considered in this light, he says.

As to the pros and cons that have been features of some so-called conductive arguments, Wohlrapp takes them to come from different frames in which an issue might be understood. For example, people looking for a person to mind their child for a few hours when they were out might understand their quest for a babysitter (translated misleadingly as 'nanny') in terms of reliability, convenience, or even as a kind of social worker project within which they hoped to provide a troubled young person with opportunities for change. From these different perspectives, a husband and wife might reason differently towards different positions as to whom they should hire. For example, the wife might regard reliability and competence as paramount considerations; for the husband, a kind of social work perspective might prevail.

Wohlrapp's counsel, in argumentation contexts where there are pros and cons, is that one should seek to dissolve the strict oppositionality of those considerations, balance various interests, and reconcile the various frames that have led to the apparent oppositionality of pros and cons. This reconciliation can be done in various ways: one may reject a frame on the basis of criticism; establish a hierarchy of frames; harmonize frames; or synthesize them. Presumably all discussants would have to agree as to what the different frames were and how they were reconciled. Wohlrapp allows that there is not always a clear conclusion to a discussion of this type. On this view, what was regarded as a pro and con conductive argument represents a stage of argumentation at some point in time when supporting reasons and objections for a thesis are still on the table.

From a subjective perspective, a thesis may seem attractive, seem to close a theoretical and practical gap, and be able to motivate acceptance. However, while there are still open objec- 
tions to that thesis, it will not have validity in the sense in which Wohlrapp defines that term. The term "objection" is used broadly in Wohlrapp's account. Objections will include criticisms, counterarguments, and attempted refutations. A thesis is not valid if there are arguments against it that have not been heard and considered: there are different frames within which the issue may be construed, and the frame differences have not been overcome if there are open objections. But while an issue may remain open in the sense that there remain open objections, the question is in principle resolvable by a discussion strategy in which discussants move ahead with reasons, always willing to put their own orientation systems up for new consideration.

There is a kind of micro-macro contrast to be drawn here between Harald Wohlrapp's approach and that of many others, including myself. Like most others who have pursued themes of informal logic in papers, textbooks, and academic monographs, I have generally taken a micro approach, extracting from a discourse some particular PPC product and raising questions of interpretation and evaluation of one or other particular argument from that starting point. In contrast, Harald Wohlrapp has taken a macro approach, offering insights on the nature of science, social relationships, the nature of subjectivity and objectivity, and other broad topics. Given the ambitious and highly integrated nature of Wohlrapp's theory, I find it hard to assess one aspect of his approach at a time. I recall Isaiah Berlin's fox and hedgehog. ${ }^{2}$ The fox, Berlin said, is interested in many little things; the hedgehog is interested in one big thing. Perhaps at this point that I am more like a fox and Wohlrapp is more like a hedgehog. But there is a sense in which this contrast is an exaggerated one. The fox and the hedgehog will need to coexist and cooperate.

What can the fox say to the hedgehog, if she senses a risk that she will be overwhelmed by the hugeness of things? She can say, "wait a minute, hedgehog, just what are the details here?" I think we all have to be foxes some of the time. In fact, there is ample evidence that Wohlrapp can show fox-like capabilities when he deems them appropriate. When we are considering the merits of reasons offered for a claim, we need our foxlike skills. I would maintain that PPC representations of arguments are valuable when we are doing close analysis of specific

\footnotetext{
2 "The fox knows many things but the hedgehog knows one big thing." The notion is highly tempting, but on reflection one does have to allow that Harald Wohlrapp is both a fox and a hedgehog. His substantial theory is developed with close examination of many examples. Berlin's treatment may be found in The Hedgehog and the Fox: An Essay on Tolstoy's View of History, edited by Henry Hardy.
} 
cases. In fact such analyses can be found in Wohlrapp's work. One can see this in his detailed discussion of the Hüppe-Merkel debate about an embryo's right to life (324-345) and that concerning the position of the monarch in the French Revolution (209-229).

\section{Objectivity}

Apart from the fundamental issue of stated premises and conclusion, there is a major contested theme in the area of objectivity. Wohlrapp seeks in his account to incorporate both subjective and objective aspects in the validity of a thesis. On the subjective side, a thesis will appear valid when it provides insight into how an orientation gap may be closed, and when it can motivate acceptance (presumably by seeming to provide that insight). These aspects, however, do not guarantee the reliability or rationality of a thesis. The criterial or objective side requires something else: the absence of "open objections". When all objections to a thesis have been answered or in some way dismissed (shown, perhaps, to be irrelevant?), there are no open objections, and the thesis will be valid from the objective point of view as well as the subjective one. This validity is not a fixed quality of the thesis, for it may change when new arguments for and against it arise. The notion that a thesis could simply be valid in and by itself, and independently of any definite fixable stage of any argumentative process, is one that Wohlrapp resists.

Theorists including myself have sometimes referred to weighing the significance of various considerations understood as counting for or against a claim. Such implications of objectivity, perhaps even quantitative in nature, have been found objectionable by Wohlrapp and some others. Literal weighing and balancing are quantitative and objective, whereas the weighing and balancing of considerations are surely not. Arguably, the notion of weighing in contexts where we deliberate about pros and cons is metaphorical, as too are such notions as balancing, counting, and adding up. These and similar expressions are common in ordinary parlance and in philosophical writing about ethics, logic, policy and law. Are these expressions metaphorical? They certainly lack any literary liveliness and are surely not vivid metaphors. Do they amount to dead metaphors? As dead metaphors are they harmless in any connotations they might retain? We may note here that the expression "dead metaphor" is itself a metaphor, likely dead. But for those who would push the notion of metaphorical status to its limits, arguably living still. 
The notion of the deadness of a metaphor merits further study. Or are such expressions as 'weighing' and 'in balance' live metaphors? Or at least metaphors sufficiently alive to preserve their capacity to mislead? The matter is disputable.

One can largely avoid talking of weighing considerations by adapting one's language so as to speak of "greater importance" and "more significance". If one thinks that there are misleading quantificational aspects in "weighing", one can speak in other ways. One can say, as we often do, things like " $x$ should count for more than y" but then of course one speaks of counting which, interpreted literally, would also be quantitative. A former professor of mine, a brilliant man trained in Scotland in the analytic tradition, used to speak of factors counting against a claim, or counting in its favour. I never understood counting in this context as implicitly quantitative and implying objective measurability due to such implications. This was many years ago. Was I perhaps simply young and naïve at the time? I don't think so.

One strategy in response to critics who object to such putative metaphors is to protect oneself by adopting different language. If I were to rewrite my textbook A Practical Study of Argument, I would adopt this strategy. But I would adopt it only as a protective measure and not based on conviction or any acknowledgement that such people are correct. I actually think that they are not. I would say that such expressions as "this factor is outweighed by another" or "his absence counts as evidence for his disinterest" or "in the balance, the second account seems best" are dead metaphors if they are metaphors at all. There is no firm criterion that will allow us to pronounce an expression to be a metaphor, or to be a live or dead metaphor. Let me just say that there is, at least, a case to be made that notions such as "outweighing" and "balancing" in contexts of deliberation are either dead metaphors or not metaphors at all. I do not seriously believe that 'frame' in "frame of reference" has physicalistic implications. My point is only that these terms and my own seem to be on a par so far as metaphorical status goes. Wohlrapp is happy enough with 'frame' and unhappy with 'weighing'. He needs to explain the differential status he gives to these expressions.

It is indeed difficult to avoid all terms that could, by some critic or other, be understood to have objectivist overtones. Even the word 'open,' apparently approved by Harald Wohlrapp for use in the discussion of argumentation, can be so interpreted. So too can references to the strength or force of arguments. When we speak of other things being equal, does 'equal' have mislead- 
ing quantitative implications? If one claim is said to support another, is the notion of support physicalistic and quantitative in its connotations? Does it misleadingly suggest that an estimation of the adequacy of support should be made by an engineer? I don't think so. We can, however, see that a hostile critic could raise such issues. The strategy of avoiding language that (even arguably) has objectivist implications will not be easy to adopt, because much of the language of thought and deliberation can be alleged to have those implications.

Which expressions descriptive of deliberation and judgment are metaphorical? When are metaphors dead and when are they not? If alive, when are metaphors misleading and when are they not? Can dead metaphors be brought to life? If so, what is the significance of that phenomenon? And how significant are translation issues in such contexts? I can only leave these questions open while pointing out that they arise for many terms and not just the weighing of various pro and con considerations in argumentative contexts. I raise these points here because of their general interest. They are relevant to Wohlrapp's comments on my efforts with the notion of conductive argument, perhaps less obviously so to his own account of objectivity — unless, that is, we begin to resist the notion of a frame as too physicalistic and implicitly quantitative.

Adopters of my textbook, A Practical Study of Argument, typically trained in analytic philosophy, were sometimes resistant to the notion that there could be such things as conductive (pro and con) arguments for which the text provided no precise method of assessment. ${ }^{3}$ Some instructors resisted the very notion of conductive argument. Others recognized conductive arguments as a type, but wrote urging me to include further directions for an assessment. Attempting to accommodate their demands, I was pressed to move in that direction. The phenomenon of desiring a method of an algorithmic sort is of some interest. Many philosophers press for methods that can lead us to answers we regard as objective; we tend to do this even when that quest is inappropriate. One line of thought should clearly be resisted: we conclude that if there is no algorithmic route to solution, the problem in question does not exist. Finding many passages in editorials, speeches, and serious books and articles, in which people cited supportive and countervailing considerations in close proximity, I found conductive arguments includ-

\footnotetext{
${ }^{3}$ Wohlrapp uses the fourth edition of my A Practical Study of Argument, noting shifts from one edition to another. The latest edition, the seventh, appeared in 2010, with an enhanced version (correcting minor numbering errors) appearing in 2014. The fourth edition was published in 1997.
} 
ing both pros and cons. I acknowledged that there was no clear path to the assessment of those arguments. This situation struck many philosophers as highly unsatisfactory, providing some with a reason to deny that such arguments existed at all, insisting that they be recast in some other way-perhaps as a series of arguments that could be shown to be deductively valid if suitable premises were added to the stated ones.

Why the lack of a general method for assessment in the context of conductive arguments? From my own perspective: topic specificity and context relativity. Why the lack of objectivity in such assessment, apparent in several editions of my textbook and found so objectionable by academic users? Looking back, I would answer: the apparently subjective nature of significance or importance. From one perspective a consideration may be of great importance; from another, it may scarcely matter. For example, the consideration that a project will cost two hundred dollars may constitute a decisive objection to undertaking it, for a struggling non-profit group. From the perspective of a wealthy philanthropist considering a donation to the group, this consideration will be of little or no significance.

Wohlrapp would say that these perspectives are based on different frames. Still, I want to urge that some considerations really are more important than others. Perhaps this is a case where Wohlrapp would say different frames can be ranked: a frame in which costs are considered definitive can be ranked below another frame in which legal rights are definitive; then perhaps that frame can be ranked lower than another in which moral rights are definitive. On his account, such a ranking would be objective when there are no open objections to it.

If one follows Harald Wohlrapp, the problem of conductive arguments including both pros and cons will go away. I submit, however, that this problem will be replaced by others. Such fixed PPC structures are products, not process, and as products they are not the focus of analysis in a process account. People may call such products 'arguments,' as we have been doing for a very long time. But on Wohlrapp's account these products are not appropriate objects of attention. We can make them disappear by focusing on process. When we do, there is no need for conductive "arguments" as discussed by myself and others. In fact, if we agree with Wohlrapp that "logicism" is generally objectionable, there should be no need for other "arguments" based on premises and conclusions, whether those be deductive, analogies, inductive generalizations, or inferences to the best explanation. 
One would like to find an account of argumentation providing a stance between relativism and objectivism couched in the materialistic language of weights and measures. Wohlrapp understands his account to occupy this space, allowing that what is valid from both subjective and objective perspectives may change. He says, for example,

A criterion is commonly understood to be something that can be questioned and assessed from the perspective of a disinterested observer. Things are different, however, with respect to assessing a state of argumentation. Although the absence of open objections is truly a kind of criterion, someone has to become involved in the matter in order to be able to assess whether it obtains; this kind of involvement must be deeper than, for example, hermeneutic efforts at interpreting a text. (285)

It may appear at one stage of a discussion as though a thesis is valid in the sense that there are no open objections to it. But that could change. For many issues and problems, different people take different perspectives or frames, as Harald Wohlrapp would put it. We speak of pros and cons precisely when there are different ways of looking at an issue that calls for decision, and when insisting on a single perspective would amount to tunnel vision. There is no one perspective that is demonstrably the "right" or "most appropriate" one. It makes sense to consult, to think and deliberate together. This is a point that Wohlrapp emphasizes, and I agree.

\section{Conclusion}

I urge at this point that it is still reasonable to understand arguments as having premises and conclusions that can be adapted, rejected, considered and revised, by persons deliberating in quest of reasonable decisions. There are matters of judgment, and we can have reasons for our judgments. There are indeed valuable, and indispensable, processes of argumentation. Many are involved when we encounter gaps in our knowledge and explore together how best to fill those gaps. On these points, Harald Wohlrapp's reflections have much to offer. What I do not accept, and do not find in a complete sense even in his highly original and thoughtful account, is the claim implied in his resistance to what he calls "logicism": that a premise/conclusion analysis is objectionable and can be eliminated. 
222 Trudy Govier

\section{References}

Govier, Trudy. 1985, 1988, 1992, 1997, 2001, 2005, 2010, 2014. A Practical Study of Argument. Wadsworth, Belmont, CA and Cengage, Boston, MA..

Hardy, Henry, Editor. (2002) The Hedgehog and the Fox: An Essay on Tolstoy's View of History. Princeton: Princeton University Press.

Wohlrapp, Harald. (2014) The Concept of Argument: A Philosophical Foundation. Dordrecht: Springer. 